\title{
DE LO RURAL A LO URBANO: "EL CASO DE DOS PROVINCIAS DE LA REGIÓN CAPITAL COMO GEOGRAFÍA DE LA TRANSFORMACIÓN SOCIOAMBIENTAL. PERCEPCIONES DESDE LA COMUNIDAD"."
}

\author{
Miguel Ricardo Landínez León ${ }^{2}$
}

Recibido el 3 de marzo de 2014, aprobado el 22 de agosto de 2014 y actualizado el 28 de abril de 2015

DOI: 10.17151/luaz.2015.41.6

\section{RESUMEN}

Objetivo: Presentar algunos hallazgos relacionados con el proceso de integración regional Bogotá-Cundinamarca en el periodo 2000-2010, en particular la dimensión ambiental, en las provincias de sabana occidente y sabana centro que hacen parte de esta región. Metodología: El estudio se basa en el análisis de los cambios presentados en el ambiente natural de los territorios objeto de estudio, durante el periodo de tiempo considerado (2000-2010), desde la perspectiva de los actores del mismo. En este caso, a través de ejercicios de participación en talleres realizados en los municipios objeto de estudio con dichos actores (representados en organizaciones sociales que tienen presencia allí) e incluyó recorridos en dichos territorios. Se pretende construir colectivamente información y conocimiento, planteando una línea del tiempo en la que los actores reconozcan momentos clave con referencia a dos grandes fenómenos que se presentaron: asentamientos humanos (urbanización) y entrada de empresas. Esta línea abarca la primera década del presente siglo. Resultados: La investigación intenta mostrar que dos elementos: asentamientos urbanos y entrada de empresas, son las dinámicas antrópicas que impactan los territorios, olvidando el elemento agua, como eje fundamental sobre el cual debería ordenarse el territorio. De ello se deriva que la misma comunidad reconoce que el ordenamiento del territorio nunca consultó sus intereses.

\section{PALABRAS CLAVE}

Integración regional, macrovectores, economía ecológica, activos naturales, gobernanza del agua.

\section{FROM THE RURAL TO THE URBAN: THE CASE OF TWO PROVIINCES IN THE CAPITAL REGION AS THE SOCIO ENVIRONMENTAL GEOGRAPHY TRANSFORMATION. INSIGHTS FROM THE COMMUNITY.}

\section{ABSTRACT}

Objective: regional integration in the period 2000-2010, particularly the environmental dimension in the Western and Central Bogotá-Cundinamarca Savannah. Methodology: The study is based on the analysis of the changes shown in the 
natural environment of the territories under study during the period considered (2000-2010) from their actors' perception..In this case, through the participation exercises in workshops carried out in the municipalities under study with those actors (represented in social organizations present in the area), and included tours around those territories It is intended to collectively build information and knowledge presenting a timeline in which the actors recognize key moments with reference to two major events: Human Settlements (urbanization) and enterprise arrival. This line comprises the first decade of the current century. Results: The research attempts to show that two elements, urban settlements and enterprises arrival, are the anthropic dynamics that impact the territories forgetting the water element as the fundamental axis from which the territory should be planned. From this it is derived that the community recognizes that land use planning never consulted their interests.

\section{KEY WORDS}

Regional Integration, macrovectors, ecological economics, natural assets, water governance.

\section{MARCO CONCEPTUAL}

El presente trabajo pretende tener una visión de lo que ha sucedido en relación con el uso, cuidado y explotación de los recursos naturales de los territorios en cuestión, a partir de una mirada integral, en la que se entiende que toda actividad desarrollada por el hombre impacta su medio natural. En este caso, se apoyó en los fundamentos generales de la economía ecológica -EE- (Castiblanco, 2007; Gómez, 2010), en tanto explicación de aspectos relacionados en la(s) interacción(es) entre sistema natural y sistema humano. No se trata de una investigación cuya base central sea la aplicación de la EE, sino que sus bases orientaron la mirada en el fenómeno observado.

El análisis de lo ambiental y de su transformación en el territorio, supone un determinado enfoque teórico respecto a la economía. Para este caso, se parte de la crítica a la noción del crecimiento, entre la cual la economía ecológica juega un papel fundamental.

Para la EE toda actividad económica se interrelaciona inevitablemente con la naturaleza. De ahí que se constituya en el estudio de las interacciones de los sistemas ecológicos y los sistemas económicos (Common \& Stagl, 2010, p. 1). La EE plantea que la actividad humana es gasto de energía, un sistema económico es gasto de energía. Pero ese gasto, que para el caso es consumo, no puede ser explicado por la biología humana, sino por la economía, la política, la cultura y las diferencias sociales (Martínez, 1998, p. 10).

Entonces, el ser humano establece interacciones sociales en su proceso "económico" que altera la base natural sobre el que este 
se sustenta. Por eso, el campo de la economía es también el campo de la ecología y viceversa (Common \& Stagl, 2010, p. 1). Es necesario mencionar estas cuestiones porque sin duda el gran proceso de crecimiento de la región, en particular el de la capital (Bogotá) y sus municipios aledaños, que ocupan el interés de este estudio, son la expresión de un sistema económico que inevitablemente ha alterado los recursos naturales de la región. ${ }^{3}$

El proceso económico no es algo que se produce simplemente para volver a reproducirse sino que, al considerarse un sistema abierto -es decir interrelacionado- que usa recursos naturales y produce deshechos (Martínez, 1998, p. 13), supone una pérdida que la contabilidad formal de la economía ha ignorado. Como se verá más adelante, los recursos naturales de los municipios han sido trastornados por el avance del crecimiento "industrial" y de urbanización, comprometiendo la sustentabilidad de los territorios, en nombre del "desarrollo económico". Dicha pérdida, no aparece como una depreciación o amortización que la compense (Martínez, 1998, p. 22). Se parte del criterio, entonces, de que los recursos naturales y fuentes de energía son "inagotables". Los economistas tendrían que analizar estos fenómenos no como un simple costo ambiental (a la manera de la economía ambiental), sino como interacciones complejas del sistema económico y el biofísico.

De manera que se tiene un enfoque sistémico en tanto que los procesos de integración regional son vistos como procesos socioeconómicos cuyos efectos se despliegan en el territorio de diversas maneras, con distintas intensidades y en variados ámbitos. Se comprende que la acción de los actores del territorio es la que provoca los cambios socioeconómicos y ambientales, sean positivos o negativos.

La adopción de este enfoque, se asume incluso por las instituciones que se encargan de la protección del medio ambiente. Así, utilizan la técnica de macrovectores, método de análisis integral que aborda los impactos de las actividades del hombre, es decir de la economía, sobre dos sistemas: el biofísico y el cultural (Corporación Autónoma de Cundinamarca -CAR-, 2004).

El macrovector se concibe "como cada uno de los procesos socioeconómicos que, sumados, constituyen la forma como el territorio es ocupado y transformado y sus recursos naturales utilizados" (CAR, 2004, p. 21). De manera más concisa, el macrovector es considerado "[...] como la actividad socioeconómica que por su importancia tiene la capacidad de generar cambios a gran escala y modificar la estructura territorial" (CAR, 2004, p. 34). Ello supone que el territorio al ser ocupado y explotado genera conflictos referidos a la incompatibilidad entre el uso natural del suelo y el uso que se le da, a prácticas deficientes o aplicación de tecnologías inadecuadas (CAR, 2004, p. 31). La Figura 1 muestra tal dinámica, en tanto referente de análisis. 


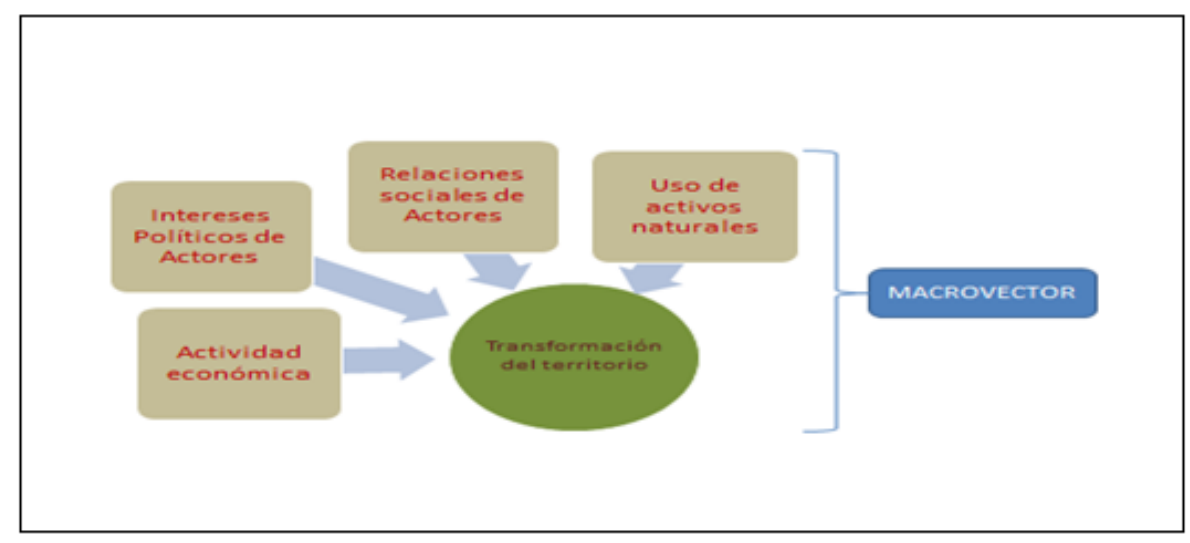

Fuente: El autor con base en CAR (2004).

Figura 1. Componentes e interacciones del macrovector.

Si partimos de la noción de territorio como un espacio-tiempo (Tomadoni, 2007); en el territorio, el espacio, ocurre un proceso, un cambio, dice esta autora, en donde se presentan mutaciones de su naturaleza que ocurren a través del tiempo. La acción humana genera transformaciones que espacial y temporalmente explican la emergencia de nuevos territorios. En el mismo sentido, Fals Borda (2000) concluye que por eso el territorio es una construcción social. Ello supone también que las regiones construyen dinámicas que las conducen a un tipo de justicia espacial (Soja, 2006) con diferenciaciones en el acceso al espacio, a su uso, disfrute, etc.

En consecuencia, solo cuando se concibe la acción económica en función de otra serie de elementos que contribuyan al bienestar social e individual, se puede hablar de algo parecido al desarrollo. Ya se sabe que justamente la actividad humana, y en especial la realizada por las economías de crecimiento, ha provocado la cada vez más rápida y sostenida desaparición de ecosistemas completos ${ }^{4}$. ¿Podría esto considerarse desarrollo?

\section{Sobre la cuestión de la urbanización}

El proceso de urbanización (asentamientos humanos) se entiende como el proceso de consolidación y expansión de centros de poblamiento cuyas características transforman el hábitat natural y es la base de reproducción del modelo actual (CAR, 2004). La emergencia de la ciudad, que ha sido por excelencia el elemento sobre el cual se ha movido el capital (Lefevbre, 1993; Von Martin, 1993; Naredo, 2002; Harvey, 2007) ha pasado por transformaciones funcionales al mismo. En la fase actual del capitalismo se presenta una participación dominante en la economía global que ha conllevado a una revaluación de los territorios dentro de este sistema; lo nacional se debilita y la mundialización explica la aparición de otras escalas espaciales (Sassen, 2001). Por supuesto, hablamos de las regiones y las ciudades. La ciudad es global, al decir de esta autora, por todos estos elementos. 
Las ciudades, en este nuevo orden y fase de la economía global, constituyen espacios vitales para la producción en red, la información, la tecnología, la concentración en el espacio urbano con actividades especializadas, características atribuibles todas a la ciudad. Desde fines del siglo pasado, por ejemplo, a Bogotá se le viene exigiendo estar en consonancia con estas nuevas realidades de la globalización.

Es un hecho que el mundo se está urbanizando. Más del $80 \%$ de la población mundial se aglomera en centros urbanos y esto constituye un fenómeno crucial en el andamiaje del capitalismo y, en consecuencia, de la vida social y política. Sin duda, la dinámica económica del capital globalizado determina en gran medida este fenómeno. La ciudad, entonces, tiene una fuerza centrípeta porque atrae todas las actividades, conformando economías de aglomeración, las empresas tienden a estar juntas, lo que a su vez, conduce a una lógica en la que estas buscan áreas densamente industrializadas (Boix, 2004, p. 7) que finalmente generan o acrecientan estas fuerzas de atracción.

Las ciudades son las madres del desarrollo económico, no porque la gente de las ciudades sea más inteligente, sino debido a las condiciones de densidad. En las ciudades hay una concentración de las necesidades y un mayor incentivo a lidiar con los problemas de un modo en que antes no se había hecho. (Jane Jacobs, citado por Soja, 2006, p. 44)

No obstante, ello no implica que la región sea contraria a la ciudad. Como se verá más adelante, más bien establecen en su dinámica la emergencia de un complejo sistema territorial. La ciudad y su fuerza centrípeta generan reconfiguraciones territoriales que provocan regiones urbanas o una especie de urbanización de las regiones.

\section{MARCO METODOLÓGICO}

Es importante aclarar que este trabajo, de ninguna manera, pretendió ser un estudio sistemático de impacto ambiental en la región Bogotá-Cundinamarca, ni la aplicación rigurosa de una metodología para la evaluación del mismo en el territorio, ni la aplicación de los métodos de la EE.

Por supuesto, se acude a la consulta de algunas fuentes secundarias y primarias. La posibilidad de realizar un análisis a través de indicadores es imposible. Al respecto, Landínez (2011) encuentra que el nivel de indicadores ambientales en Colombia para unidades territoriales (como regiones o municipios) es casi inexistente y los diversos indicadores que se usan a nivel agregado (nacional) corresponden a los que la institucionalidad mundial utiliza. ${ }^{5}$ 
En consecuencia, la información que este trabajo presenta, se recogió con trabajo de campo, que abarcó recorridos de los municipios y talleres participativos con organizaciones sociales y funcionarios que allí tienen presencia. Se hicieron 2 tipos de talleres: uno que recogía las apreciaciones iniciales y conocimientos acerca del tema de los actores a partir de preguntas estructuradas, pero que durante el desarrollo del taller se iban trabajando a través del diálogo participativo (Anexo 1). En el segundo taller, en el que se validaba la información analizada, se presenta una gráfica con una hipótesis derivada de la conclusión del primer taller y una serie de consideraciones a partir de las cuales se validaba, debatía o se complementaba la información anteriormente recogida (Anexo 2).

El trabajo, por otra parte, siguió las orientaciones de Márquez (2001) que consisten en una interpretación ambiental de los fenómenos descritos y su interconexión con los cambios sociales, culturales, económicos, para dar cuenta de las grandes transformaciones ocurridas. Basados en la información de los talleres y bajo el enfoque teórico descrito, se avanza en esa dirección.

En resumen, se trata de relacionar una serie de actividades realizadas por el hombre, cuyos impactos se reflejan en los sistemas biofísico y ambiental. De acuerdo con la CAR en el documento que se ha reseñado, se han definido los siguientes macrovectores para la región, agrupados temáticamente:

Tabla 1. Macrovectores y áreas temáticas

\begin{tabular}{|c|c|}
\hline Macrovectores & Areas temáticas \\
\hline $\begin{array}{l}\text { - Agricultura tradicional } \\
\text { - } \text { Agricultura comercial } \\
\text { - } \text { Agroindustria } \\
\text { - } \text { Ganadería de especies menores } \\
\text { - } \text { Ganadería de especies mayores }\end{array}$ & Desarrollo agropecuario sostenible \\
\hline - Industria & Desarrollo industrial sostenible \\
\hline - Explotación minera & Manejo ambiental de la minería \\
\hline - Transporte & Manejo sostenible del transporte \\
\hline $\begin{array}{l}\text { - Turismo y recreación } \\
\text { - Asentamientos urbanos }\end{array}$ & Desarrollo urbano sostenible \\
\hline $\begin{array}{l}\text { - Explotación de hidrocarburos } \\
\text { - Producción / Utilización energía }\end{array}$ & Uso sostenible de la energía \\
\hline - Explotación forestal & Ecosistemas estratégicos y biodiversidad \\
\hline - Agua y materiales & Manejo del ciclo del agua y ciclo de materiales \\
\hline
\end{tabular}

Fuente: El autor con base en CAR (2004).

Según la estructura metodológica establecida por la CAR, el agua y los materiales se encontraban transversales a todos los procesos productivos (CAR, 2010). De otra parte, hay que entender que la relación no es biunívoca, sino que cada macrovector puede afectar a otros o es afectado por varios de ellos. 
Desde ese punto de vista, se hizo necesario identificar los actores por cada macrovector. En este caso sería como lo indica la Tabla 2.

Tabla 2. Actores por macrovector

\begin{tabular}{|c|l|}
\hline \multicolumn{1}{|c|}{ Macrovector } & \multicolumn{1}{|c|}{ Actores } \\
\hline & Alcaldías \\
\hline Manejo del ciclo del agua & Empresas públicas \\
& Empresas privadas que suministran agua \\
& Acueductos comunitarios \\
& Organizaciones comunitarias \\
\hline Manejo ciclo materiales y residuos sólidos & Empresas privadas \\
& Empresas que manejan basuras \\
\hline Ecosistemas estratégicos & Alcaldías \\
& Empresas turísticas \\
\hline Desarrollo urbano sostenible & Constructoras \\
\hline & Empresas constructoras \\
& Alcaldía \\
\hline
\end{tabular}

Fuente: El autor con base en CAR (2004).

Ahora bien, de todos los macrovectores descritos y propuestos por la CAR, se han seleccionado dos: Urbanización (asentamientos humanos) e Industrialización.

Esto tiene una razón: el proyecto partió de una hipótesis general, la cual planteaba la existencia de dos elementos que, dada su enorme fuerza económica, incidían en el proceso de integración Bogotá-Cundinamarca, tanto para sus avances como para sus retrocesos: industrialización y urbanización. En consecuencia, el proyecto planteó una "hipótesis-pregunta" general que se propuso a la comunidad. ¿En qué medida, el ordenamiento del territorio de sabana centro y de occidente ha estado condicionado por el proceso de urbanización y la entrada de empresas?

Con base a esta apuesta, se hizo el acercamiento a la comunidad cuyas características metodológicas y técnicas se explican a continuación.

\section{Realización de talleres con actores locales}

En primer lugar, la idea base es la consecución de información cualitativa, a través de la realización de talleres entendidos como espacios colectivos en los que la comunidad (actores locales) expresa sus percepciones, conocimientos y experiencias en relación con los procesos de transformación de sus territorios durante el periodo considerado.

Los asistentes fueron personas pertenecientes a organizaciones sociales que participan activamente en la vida de sus territorios y 
que, en consecuencia, presentan un nivel de conocimiento histórico de los mismos en sus diversas manifestaciones económicas, ambientales, sociales, etc. Se estableció una línea del tiempo (1998-2010) en la cual se ubicó a la comunidad para que identificara los hitos fundamentales en el proceso de transformación de los municipios. A partir de unas preguntas estructuradas que sirven de guía (Anexo 1), se elaboran otras "orientadoras" (Anexo 2) las cuales se formulan directamente a los asistentes; en la medida en que avanza el taller se van profundizando temas específicos. La dinámica permite desarrollar una conversación, debate, en la que finalmente hay un contexto con puntos de vista, no siempre convergentes, pero que dan una apreciación muy coherente sobre los acontecimientos objeto de investigación.

\section{Entrevistas no estructuradas con funcionarios}

Bajo la misma lógica de indagar con actores sobre las dinámicas ocurridas, en este caso se visitaron las alcaldías de los municipios para conversar con funcionarios y obtener información cualitativa. Las preguntas son las mismas del Anexo 1, además de otras que intentan dar cuenta del proceso que ha vivido cada entidad municipal en particular.

En general, se intenta tener una visión de una misma realidad, pero vista desde diferentes perspectivas.

\section{EL TEMA DE LA INTEGRACIÓN BOGOTÁ-REGIÓN}

Bajo el paradigma de la globalización se plantea que los territorios, de modo interdependiente, asociativo, solidario, pueden alcanzar mejores estándares sociales y económicos. En ese orden de ideas, los territorios, conjuntamente pueden y deben consolidar una identidad cultural y social. Bogotá y la región no han sido ajenas a esa idea y han dado los pasos para este fin, aunque son evidentes las dificultades políticoadministrativas e institucionales para alcanzar estos propósitos.

Desde luego, los ritmos y grados de la dinámica de la integración los impone Bogotá. Por su potente dinámica urbanística y económica, la capital irradia efectos igualmente fuertes sobre su entorno territorial inmediato con municipios que no alcanzan a tener respuestas sólidas, claras, de largo plazo y acorde a sus necesidades y expectativas que, al mismo tiempo, converjan en sus políticas hacia un proceso de integración regional.

La construcción y expansión de Bogotá, no ha obedecido a procesos sistemáticos de planeación, ni mucho menos ha sido producto de acciones concertadas, participativas y democráticas de todos sus ciudadanos. En general, la ciudad se creó a instancias de los intereses de las clases sociales dominantes y de grupos económicos con alto poder de injerencia y decisión en el Estado. 
Este crecimiento inusitado y vertiginoso, que comienza a vislumbrarse a comienzos del siglo $X X$ y que toma dramática forma a partir de mediados del mismo, necesariamente determina la aparición de fenómenos sociales, ambientales de alta complejidad (Preciado, 2007). La ocupación de un territorio supone también formas de uso del suelo, explotación de activos naturales, con su eventual alteración al ecosistema. La expansión de Bogotá no solo ha venido alterando significativamente su entorno inmediato, sino que también viene causando problemas en toda su área de influencia.

Llama la atención que, por ejemplo, la Gobernación de Cundinamarca asuma, precisamente, el contexto de la conformación de la región a partir de la geografía económica (Gobernación de Cundinamarca, 2010, p 14). Aunque menciona la cuestión del desarrollo humano, sin duda lo económico es el factor principal que guía este proceso y alrededor del cual se ordena el territorio. Es por ello que teóricos como Soja (2006) plantean que hay que analizar estos fenómenos desde una perspectiva geográfica, política y económica, dando una visión que él propone llamar "economía geopolítica".

Por ello, como ha sucedido con la región capital, se puede interpretar como un fenómeno de sinecismo ${ }^{6}$, de una fuerza centrípeta ejercida por una ciudad que atrae a otras poblaciones, las articula en su lógica y dinámica socioeconómica y espacial, para crear un nuevo espacio, múltiple, diverso, complejo, contradictorio, caótico, pero al mismo tiempo expresión de una dinámica de "aglomeración humana" (Soja, 2006).

En virtud de la visión de planificación y ordenamiento del territorio, la escala espacial de la región se ha delimitado o establecido en tres ámbitos:

- Región Metropolitana: Distrito y Municipios.

- Región Capital: Distrito y Cundinamarca.

- Región Central: Distrito, Cundinamarca, Boyacá, Meta, Tolima.

Para esta investigación, se trabajó desde la noción de Región Capital en virtud de la cual Bogotá, como centro urbano principal y enorme poder, atrae y forma con los municipios del departamento un territorio con características y condiciones económicas, sociales, ambientales, culturales muy específicas que le confieren una "vida" única. Igualmente, que es un proceso claramente intencionado en tanto que "[...] se destaca que la región capital Bogotá-Cundinamarca se ha desarrollado en un marco de confianza interinstitucional entre las administraciones distrital, departamental y municipal" (Gobernación de Cundinamarca, 2010, p. 10).

Naturalmente que pueden ser muchas las discusiones alrededor de lo que es Región Capital, pero sin duda aquí nos inscribimos, en términos generales, a lo que se viene trabajando para la región. 


\section{DINÁMICAS DEL CRECIMIENTO QUE INCIDEN EN TRANSFORMACIONES AMBIENTALES}

Como se ha dicho, la ocupación de un territorio implica el uso (demanda) de sus recursos naturales. La medida y forma en que estos se utilicen está íntimamente relacionada con el modelo económico que impere. La base de este trabajo no es considerar que toda acción humana es en sí nefasta para el medio ambiente sino que depende, precisamente, de la visión de ese modelo.

Colombia no escapa a esta lógica. En las últimas dos décadas se ha impuesto el modelo neoliberal. Este ha debilitado las formas de regulación y control que desde el Estado hubieran podido impedir la ocupación del territorio de manera no solo desordenada, sino además con el agravante que ha significado una desequilibrada apropiación del mismo: empresas industriales y grandes urbanizadoras han venido usufructuando la tierra y sus activos, desplazando pequeñas actividades económicas tradicionales de estos territorios, sin que al mismo tiempo se hayan compensado los nuevos desplazados, ya no por el conflicto, sino por esta forma de ocupación desligada de cualquier concepto de desarrollo humano y ecológico.

La transformación está dada por una secuencia, producto de las actividades antrópicas, que transita desde la abundancia de recursos a su inminente escasez, tal como se puede deducir del texto de Márquez citado, por lo menos para el caso colombiano y que queremos graficar así:

Figura 2. Secuencia de actividades antrópicas en el ecosistema.

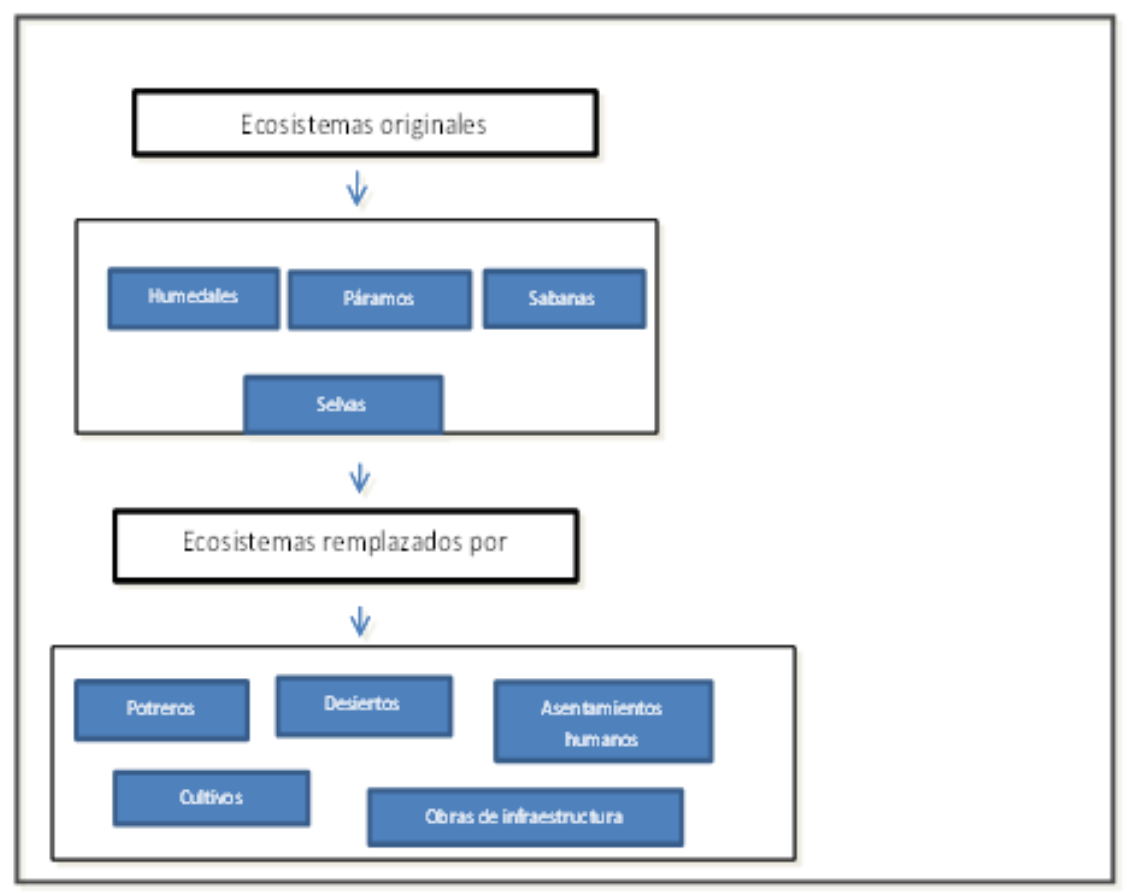

Fuente: El autor con base en Márquez (2001). 


\section{EL CASO DE LA REGIÓN CAPITAL}

Como se ha planteado desde la economía ecológica, el sistema económico no está desligado del sistema biofísico. El medio natural ha sido afectado y genera conflictos que, en el caso particular del departamento de Cundinamarca, han sido tratados, en primera instancia, por la CAR, pues de los 116 municipios que componen el departamento, 104 están bajo su jurisdicción (Preciado, 2012), constituyéndose en la primera autoridad ambiental.

Por lo demás, tanto el departamento como los municipios, adelantan acciones puntuales que corresponden al cumplimiento de sus respectivos planes de desarrollo. A propósito, Preciado llama la atención en el sentido de que, según el artículo 61 de la Ley 99 de 1993, es claro el valor que tiene toda la región en términos ecológicos. Textualmente reza: "Declárase la Sabana de Bogotá, sus páramos, aguas, valles aledaños, cerros circundantes y sistemas montañosos como de interés ecológico nacional, cuya destinación prioritaria será la agropecuaria y forestal".

Sin embargo, aquí encontramos una de las múltiples contradicciones que suelen ocurrir en el ordenamiento jurídico del país, que incluye, por lo demás el choque de intereses y de alcances de cada una de las instituciones que convergen en un territorio. Pues si bien el Ministerio del Medio Ambiente y la CAR tienen disposición sobre tipos de explotación minera, además de la protección de las áreas de reserva de los municipios, al determinar los usos del suelo pueden, como lo han venido haciendo, destinar porciones sumamente importantes de sus territorios para el uso de vivienda o industria, en muchos casos sobre terrenos que eran de vocación agropecuaria y forestal.

Esto tiene que ver, a su vez, con la planeación regional y las disposiciones legales que otorga la misma Constitución del 91, así como las leyes y decretos que reglamentan este proceso. Así, el artículo 306 de la Constitución Política Nacional (CPN) reconoce la autonomía de Bogotá y del departamento, pero facilita un camino para su integración a través de la constitución de la "región administrativa de planificación especial" (RAPE). De hecho, el artículo 319 de la CPN genera el espacio jurídico para que los municipios actúen también de manera unida:

Cuando dos o más municipios tengan relaciones económicas, sociales y físicas, que den al conjunto características de un área metropolitana, podrán organizarse como entidad administrativa encargada de programar y coordinar el desarrollo armónico e integrado del territorio colocado bajo su autoridad.

Como se observa, existen instrumentos jurídicos para que la región consolide un proceso de integración. Bajo la orientación 
de la Ley 388 de ordenamiento territorial, como se lee en Mejía (2009, pp. 24-25), el ordenamiento del territorio se hará tomando en consideración las relaciones intermunicipales, metropolitanas y regionales. Sin embargo, en la práctica, la gestión ambiental se hace de manera segmentada según los límites políticoadministrativos de los municipios, olvidando que el ecosistema, como realidad natural, desborda la lógica reduccionista de límites artificiales creados por el hombre.

No obstante, para superar estas limitaciones, desde una visión del desarrollo territorial, se ha planteado la necesidad de articular los planes de ordenamiento territorial en conjunto con los municipios del primer anillo y que se conciba además como un sistema jerarquizado de asentamientos integrados por redes viales, servicios públicos y equipamientos (Mejía, 2009, p. 24). A manera de ilustración, se presentan en la Tabla 3 los proyectos correspondientes a la dimensión ambiental que quieren significar la gestión "macro" de lo ambiental cuya responsabilidad recaería en la gobernación y el Distrito especialmente.

Tabla 3. Principales proyectos macro en la dimensión ambiental

\begin{tabular}{|c|c|}
\hline TEMA & REGIÓN CAPITAL \\
\hline \multirow{4}{*}{$\begin{array}{c}\text { MEDIO } \\
\text { AMBIENTE }\end{array}$} & $\begin{array}{l}\text { Estructura Ecológica Principal-EEP-Bogotá } \\
\text { y Cundinamarca }\end{array}$ \\
\hline & Descontaminsción Rio Bogoté PMAA \\
\hline & Proyecto Regiongl de Reforestación \\
\hline & $\begin{array}{l}\text { Prestación de servicios de scueducto y } \\
\text { slcantarillado PMAA }\end{array}$ \\
\hline HÁBITAT & $\begin{array}{l}\text { Proyecto regional de disposición de } \\
\text { residuos sólidos, rellenos sanitarios, plantas de reciclaje } \\
\text { Proyectos regionales de desarrollo } \\
\text { urbano y vivienda }\end{array}$ \\
\hline
\end{tabular}

Fuente: El autor con base en Mejía (2009, p. 113).

Al observar esta tabla se encuentra que, con base a lo comentado por la comunidad en los dos territorios (sabana centro y sabana occidente), hay un desconocimiento de estos proyectos, poco se sabe de su gestión y de sus alcances. Las opiniones y observaciones que en los talleres ofrecieron los ciudadanos, en concordancia con la "vivencia en el territorio", indican problemáticas más cercanas que tocan su cotidianidad.

El departamento de Cundinamarca cuenta con 116 municipios que en su esencia son entidades político-administrativas autónomas. Para efectos de una mejor actuación conjunta de los municipios, se ha hecho una división del departamento por provincias que "si bien no constituyen formalmente entidades territoriales con un aparato institucional público propio" (Centro de Pensamiento en Estrategias Competitivas -CEPEC-, 2011 en términos reales facilita el trabajo de los municipios que las conforman para fines comunes. En el mapa de la división 
política-administrativa del departamento, se ubican las distintas provincias, las cuales suman 15 en total (Anexo mapa 1).

Para este trabajo se tomó como objeto de análisis dos provincias: Sabana Occidente (SO) y Sabana Centro (SC). Para cada una de ellas las unidades de observación la constituyen 3 municipios: Mosquera, Funza y Madrid para SO y Chía, Cajicá y Sopó para SC. Esto se debe al hecho de estar ubicados en el primer anillo de influencia de Bogotá y tener una actividad económica y urbanística significativa, que comprende al mismo tiempo interacciones de doble vía "municipios-capital" bastante fuertes.

\section{HALLAZGOS PARA LOS TERRITORIOS CONSIDERADOS}

\section{Sabana occidente}

Sabana occidente está conformada por 8 municipios: Mosquera, Funza, Madrid, Facatativá, Zipacón, Bojacá, El Rosal y Subachoque. Se encuentra en la sabana de Bogotá, al occidente de la capital y tiene una extensión total de $1027 \mathrm{~km}^{2}$ equivalentes al $4 \%$ del área total del departamento (CEPEC, 2011, p. 15).

En cuanto a los tres municipios que se abordaron, presenta las siguientes características generales:

En conjunto tienen una población total de 225.824 habitantes, según proyecciones a 2013. Según lo muestra el Gráfico 3, son municipios que tienen la misma tendencia urbanizadora del mundo actual, pues el $92,1 \%$ se ubica en los cascos urbanos (Gráfico 1).

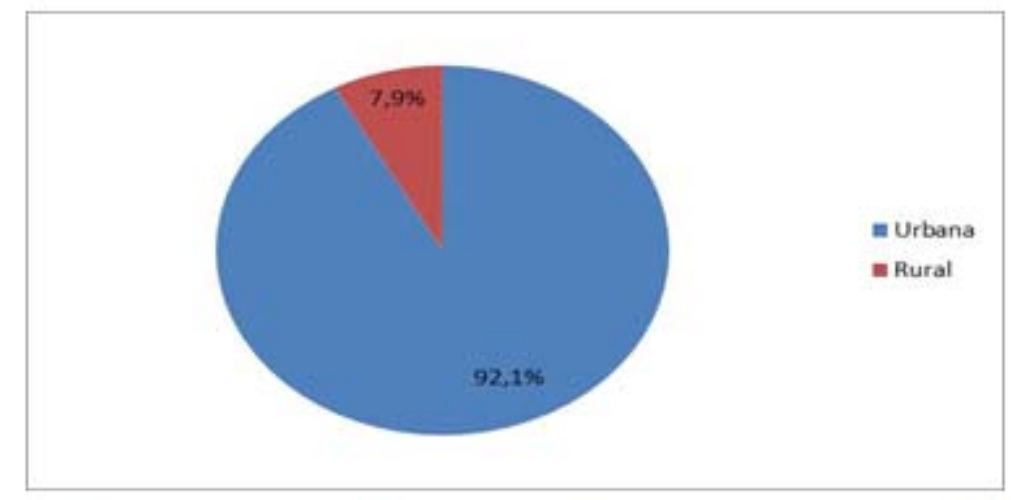

Fuente: El autor con base en Secretaría de Planeación de Cundinamarca.2014

Gráfico 1. Concentración población urbana. Sabana occidente.

Por otra parte, la extensión territorial equivale a $297,5 \mathrm{~km}^{2}$, equivalentes al $1,3 \%$ del total del departamento de Cundinamarca. Paradójicamente, hay una mayor extensión de suelo rural pues el $72,7 \%$ es rural y solo el $27,3 \%$ tiene un uso urbano (Gráfico 2), lo que evidencia otro aspecto propio de un 
mundo urbanizado: la concentración y/o aglomeración de personas en territorios extensivamente menores, en contrate con la existencia de amplias zonas rurales con mínimas densidades poblacionales.

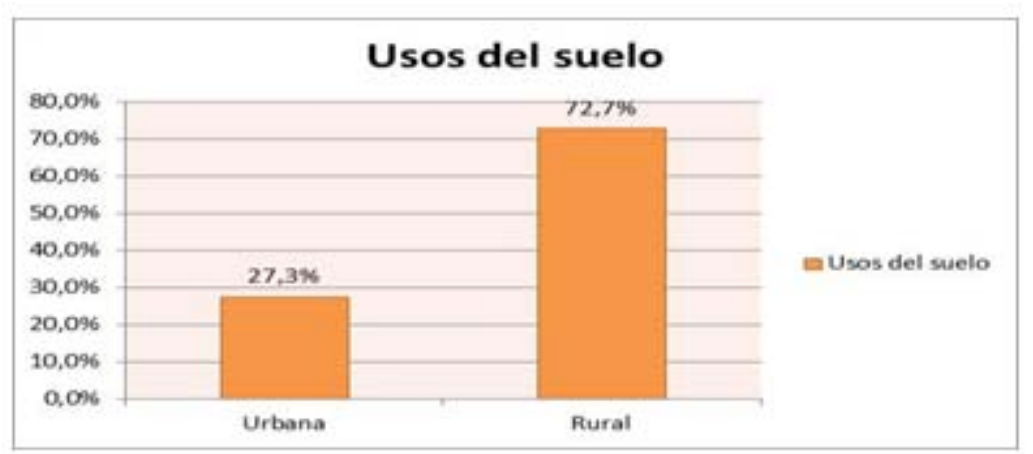

Fuente: El autor con base en Secretaria de Planeación de Cundinamarca 2014.

Gráfico 2. Usos del suelo. Sabana occidente.

Para confirmar esta tendencia, observando el total de predios de este territorio, se encuentra una concentración bastante alta de predios urbanos sobre el rural, que significa una reconfiguración territorial con expresión clara de la vocación urbana de los municipios, antaño rurales. El Gráfico 3 muestra esta concentración actual.

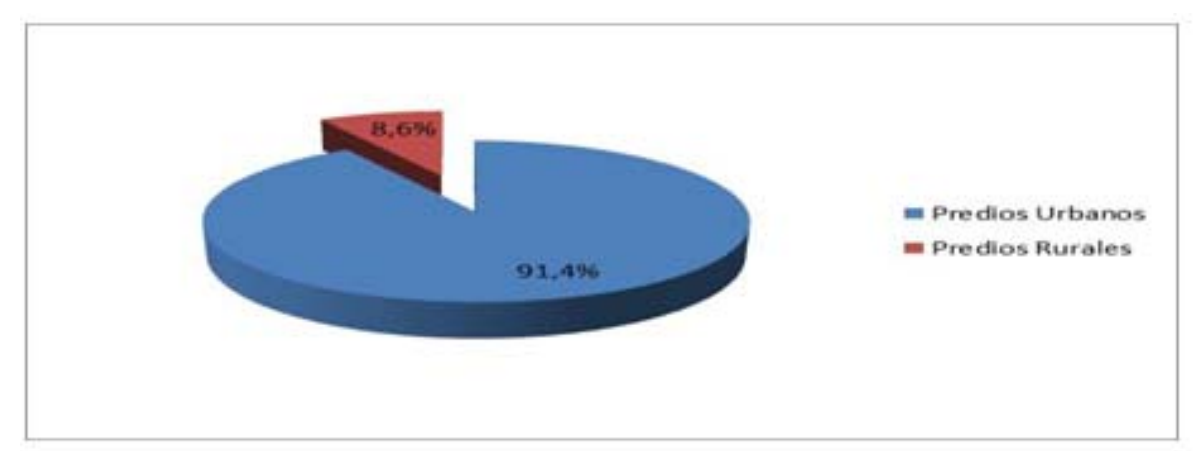

Fuente: El autor con base en Secretaria de Planeación de Cundinamarca.2014

Gráfico 3. Porcentaje de predios rurales y urbanos.

\section{Tendencias generales en 1998-2010 - Sabana occidente}

Se propone un análisis relacional con tres variables: a) el aumento de las actividades humanas (sistema económico), b) aumento sostenido de crecimiento del hábitat urbano (ocupación del suelo) y c) el aumento de la población. Tres elementos que inciden directamente sobre el ambiente físico-natural (naturaleza). Para empezar, el Gráfico 4 muestra la evolución para sabana occidente del incremento poblacional. 


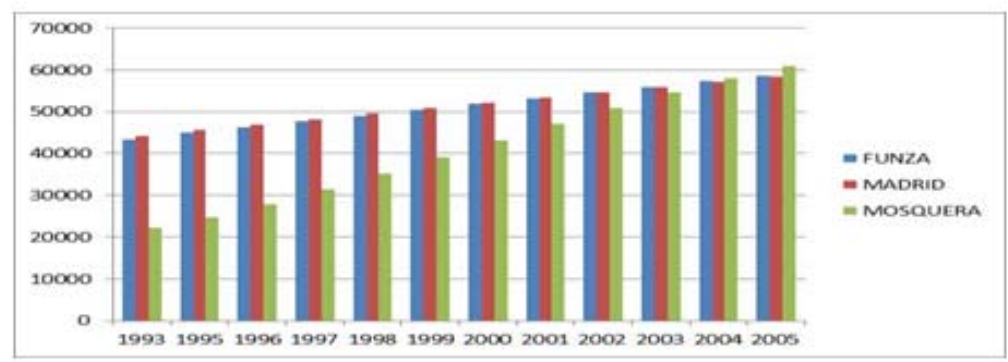

Fuente: El autor con base DANE-Estimaciones de Población Nacional, Departamental y Municipal 19852005.

Gráfico 4. Crecimiento poblacional por municipio 1993-2005

Al comparar esta tendencia con la demanda de suelo para construcción (Gráfico 5), simplemente se demuestra esa tendencia urbanizadora. Se podría argumentar que es un proceso lógico del crecimiento demográfico que se presenta en cualquier parte. Lo que se quiere sustentar es que esa tendencia no ha estado acompañada de una visión sistémica que dé cuenta de una visión sostenible de lo ambiental. Sobre esta cuestión, más adelante se aborda cuando se expongan las características generales del proceso de crecimiento Bogotá-Región, en la perspectiva de las comunidades consultadas.

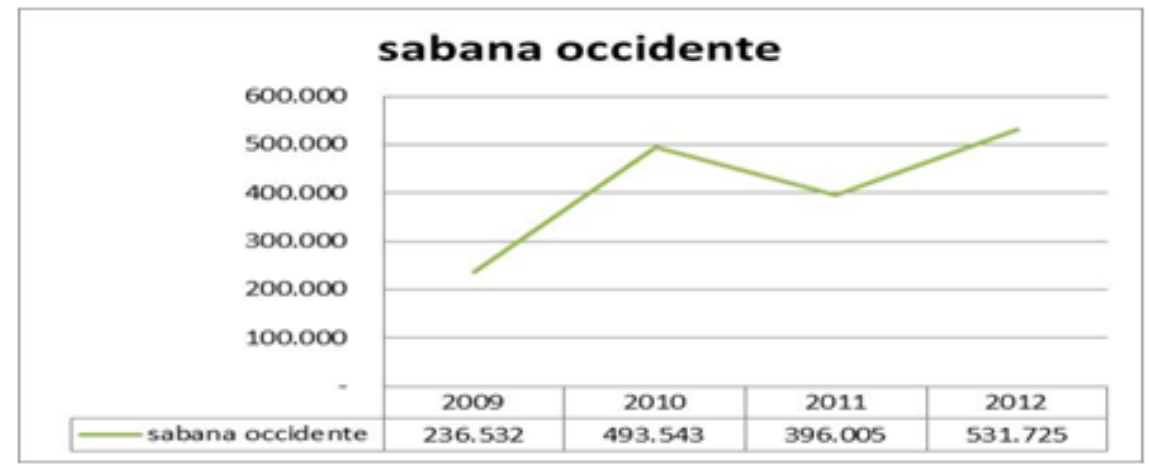

Fuente: El autor con DANE - Área aprobada construcción $\left(\mathrm{m}^{2}\right)$ por municipio.

Gráfico 5. Área aprobada para vivienda y otros destinos. Sabana occidente.

Las zonas rurales no han sido afectadas al juzgar por las cifras, pues la extensión rural sigue siendo supremamente superior en extensión a la urbana. Como se anotaba más arriba, lo urbano supone la "concentración-aglomeración", es decir, la densificación. Sin embargo, las cifras oficiales no muestran una realidad comprobada en las visitas de campo: grandes extensiones rurales han sido ocupadas para viviendas de estratos sociales altos, sin que las estadísticas cambien en cuanto a ocupación del suelo, pues se siguen mostrando como áreas rurales lo que en la práctica ya no lo es (es urbanizado) y, por tanto, pérdida de activos naturales.

En particular los municipios de Mosquera y Madrid han presentado este fenómeno para viviendas de estratos altos, pero también Funza con vivienda para estrato 3 . Es claro que la 
presión ambiental se presenta al ocupar zonas boscosas o de humedales, tal como se indicará en los hallazgos.

La génesis de la transformación más radical del territorio está en los años ochenta. Sin embargo, los hitos fundamentales comienzan en los noventa los cuales no pueden descontextualizarse del advenimiento del modelo neoliberal cuyos arreglos institucionales se hacen en Colombia finalizando los años ochenta, empezando a articular al país a los procesos de globalización (Garay, 1999) y expresado ya más claramente en Colombia con la apertura económica de los años noventa. No es posible interpretar lo que pasa en la región, sin pensar en los procesos de globalización.

Es muy importante resaltar un hallazgo que de alguna manera expresa también el verdadero desarrollo o avance de la industria en Colombia. Lo que se encuentra es que una gran parte de las empresas han instalado bodegas y trasladado algunos procesos productivos, lo que ciertamente no puede llamarse industrialización. Más bien, este trabajo lo denomina "Ilegada de empresas", pero sin que ello no signifique que se presente una incidencia negativa en los activos naturales del territorio.

Las apreciaciones que desde la dinámica ambiental manifestaron los actores se presentan en el Anexo 3. Como se puede deducir, hay una percepción casi unánime de los actores locales en el sentido de que los cambios que se han presentado, han traído en general un deterioro del paisaje natural, ocupación de humedales, pérdida de prácticas de cultivo, contaminación, afectación de fuentes de aguas, deterioro del suelo, etc.

De acuerdo con Preciado (2012), la conurbación FunzaMosquera-Madrid, cuya expansión es evidente, impacta el río Bogotá el cual se constituye en un eje regional ambiental de enorme importancia. Es decir, es un fenómeno que cada vez cobra más importancia para el futuro y que seguramente las políticas públicas no pueden seguir ignorándolo.

\section{Sabana centro}

Esta provincia la constituyen 11 municipios: Tabio, Tenjo, Cota, Chía, Cajicá, Sopó, Zipaquirá, Tocancipá, Gachancipá, Cogua y Nemocón, con una extensión total de $1237 \mathrm{~km}^{2}$ equivalentes al $6 \%$ del total del departamento. Los aspectos característicos de este territorio se presentan a continuación.

Según proyecciones de la Secretaría de Planeación de Cundinamarca 2014 el total de la población para los tres municipios de análisis asciende para 2013 a un total de 200.880 habitantes. Como se observa en el Gráfico 6, contrario a lo que sucede en sabana occidente, se encuentra que la proporción de población rural con respecto a la urbana, es más marcada en sabana centro. Si se tiene en cuenta que ha habido un fuerte proceso de urbanización, aparentemente debería presentarse un comportamiento similar. Como se ha anotado, es probable que muchos predios no hayan sido asimilados a uso rural (ver 
Gráfico 7), lo que indica que aunque en la práctica se ha urbanizado, se siguen presentando cifras con carácter de rural lo que incidiría también en el cálculo de este tipo de proporciones.

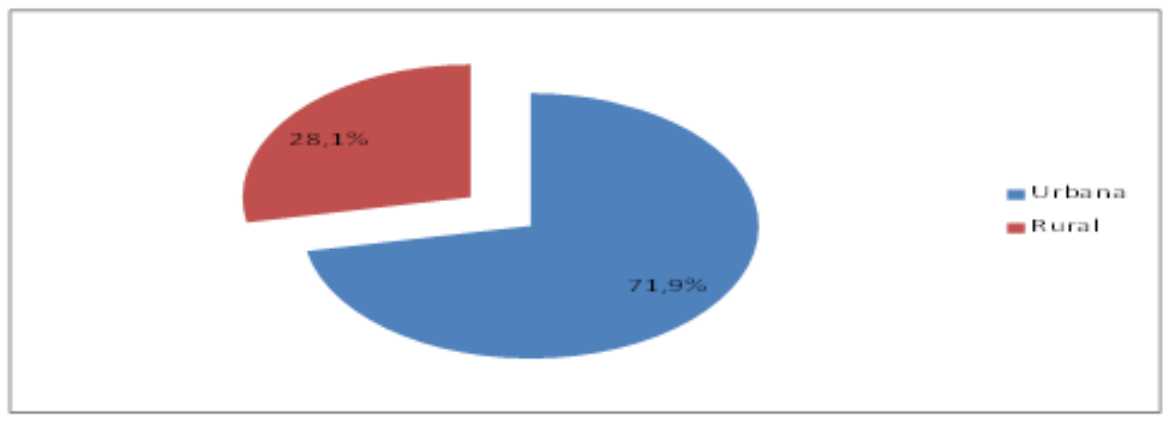

Fuente: El autor con base en Secretaría de Planeación de Cundinamarca.2014

Gráfico 6. Concentración población urbana. Sabana centro.

Respecto a la extensión territorial, siguiendo la lógica de lo que se ha dicho, solo un $4,1 \%$ ha sido catalogado como urbano (Gráfico 7). Es decir, persiste la inquietud de cómo se puede analizar esta cifra, ante el evidente proceso de construcción sobre suelo rural. Aunque la población urbana, ha aumentado significativamente, no el suelo urbano. Al parecer, se encontraría este territorio ante un fuerte problema de densificación. Insistimos, sin embargo, que se trata de unas estadísticas que siguen considerando rural, lo que en la práctica es urbano.

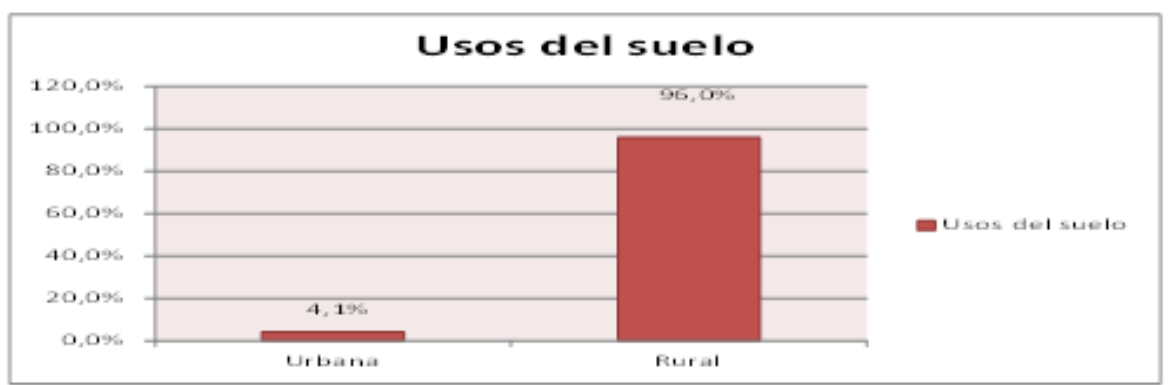

Fuente: El autor con base en Secretaría de Planeación de Cundinamarca 2014

Gráfico 7. Usos del suelo. Sabana centro.

Es significativo que este territorio, al cual ha llegado un agresivo proceso de construcción, en especial de viviendas para grupos de alto poder adquisitivo, persista en considerar una extensión bastante grande como rural. Por las indagaciones con la comunidad, así como por el análisis de la publicidad de las empresas constructoras, estas hacen más atractivos sus proyectos de vivienda, al venderlos como "ubicados en tranquilas zonas campestres", lo que sin duda aumenta sus ganancias, pero que se traduce en pérdida ambiental y ecológica. Tal como lo manifiestan las organizaciones de la comunidad, se ha deteriorado el suelo y se han desplazado actividades agrícolas propias de estas regiones. 
El Gráfico 8 señala la proporción entre predios rurales y urbanos. En concordancia con lo mencionado respecto a la consideración de cifras, siguiendo la tendencia urbanizadora, debería presentarse una mayor proporción de predios urbanos, sin embargo, estos son los datos actuales que se presentan desde la Secretaría de Planeación de Cundinamarca.

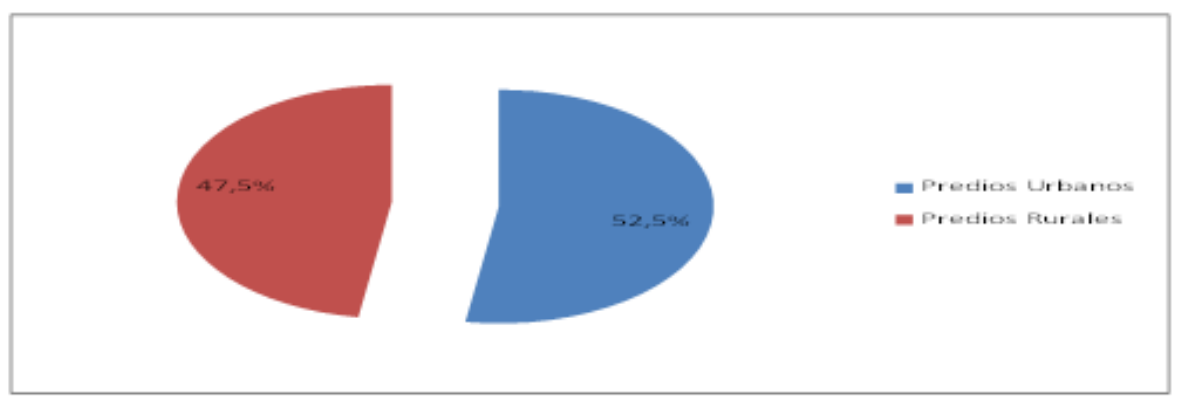

Fuente: El autor con base en Secretaría de Planeación de Cundinamarca 2014

Gráfico 8. Porcentaje de predios rurales y urbanos.

\section{Tendencias generales 1998-2010}

Tomamos, como en el caso anterior, entonces las tres variables básicas indicadas en el apartado: Tendencias generales en 1998-2010 - Sabana occidente.

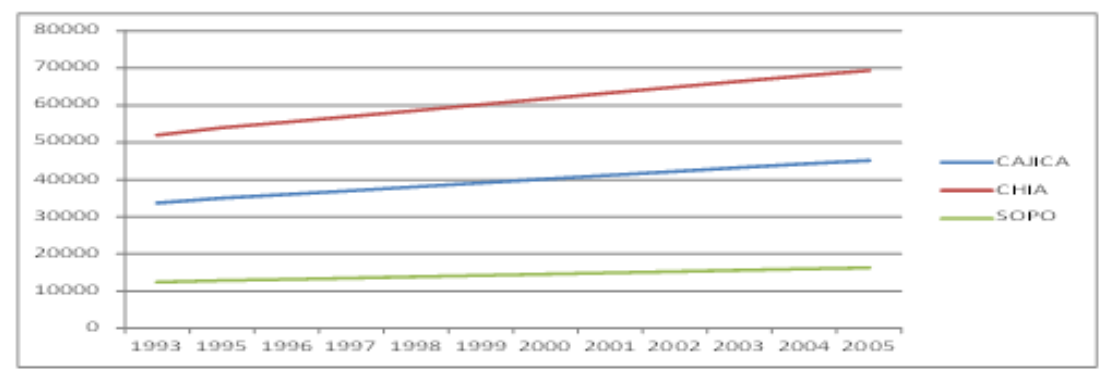

Fuente: El autor con base en DANE-Estimaciones de Población Nacional, Departamental y Municipal 1985 2005.

Gráfico 9. Crecimiento poblacional por municipio 1993-2005.

La tendencia -al igual que en sabana occidente- es al crecimiento, por lo que el proceso de urbanización es innegable, en particular Chía y Cajicá son los municipios que soportan esta tendencia, tal como lo muestra el Gráfico 9.

Por otra parte, el área aprobada para vivienda y otros destinos obviamente que ha aumentado, aunque se muestra una tendencia a la baja para el año 2012 (Gráfico 10). Esta situación contrasta, sin embargo, con el inusitado crecimiento en proyectos para vivienda en Cajicá tal como se evidencia en las visitas de campo y en las declaraciones de la comunidad en los talleres realizados con esta. En realidad, ya se ha agotado mucho del suelo urbanizable en Chía y el fenómeno se ha trasladado a Cajicá. 
El proceso ha conducido, además, a la presencia de construcciones y equipamientos en estos dos municipios con un alto grado de contaminación visual, auditiva y ambiental.

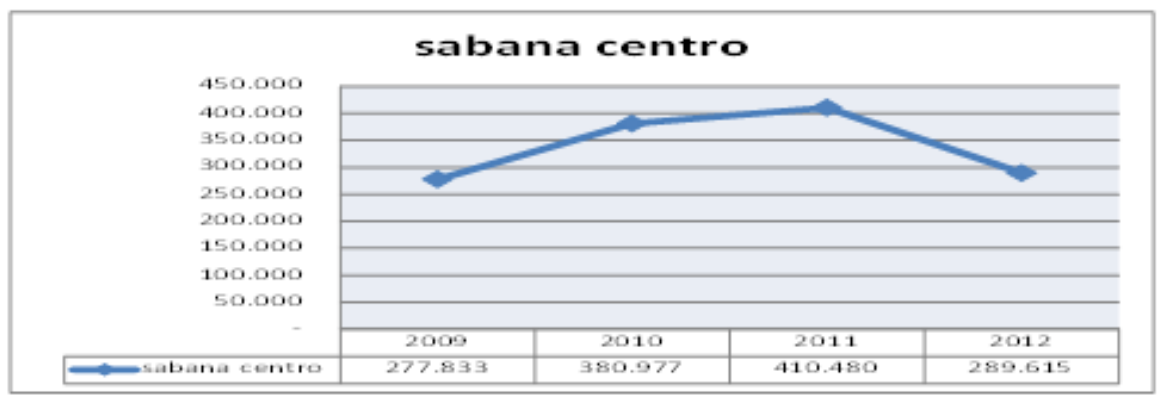

Fuente: El autor con base en DANE - Area aprobada construcción (m²) por municipio.

Gráfico 10. Area aprobada para vivienda y otros destinos. Sabana occidente.

La manifestación más clara de las transformaciones se da en el auge de los proyectos urbanísticos que comienzan a desplazar las actividades agropecuarias, a cambiar la cultura, las tradiciones y a impactar el medio natural.

Llama la atención que el proceso de construcción de viviendas y de ocupación del suelo para actividades de servicios de alto costo (restaurantes, discotecas, concesionarios, supermercados, universidades, etc.) se ha desplazado al municipio de Cajicá. Las acciones que mitiguen el impacto ambiental no han sido de la misma intensidad. Por ejemplo, los participantes en diversos momentos manifestaron su preocupación por la ausencia de un plan para el montaje de una planta de tratamiento de residuos sólidos y de un relleno sanitario. Gradualmente, los habitantes ven cómo el crecimiento inusitado de los municipios está generando una carga de deshechos que pueden llegar a crear un grave problema para la región en términos ambientales.

Las deficiencias en la malla vial y la construcción en zonas más bajas a la cota del río Bogotá, seguirá causando los problemas de inundaciones como aquellas que se presentaron durante la primera ola invernal, de no tomarse medidas más estructurales, políticas e institucionales que pongan freno al descontrolado proceso de crecimiento urbano que presentan los municipios de Cajicá y Chía, especialmente.

\section{LECCIONES APRENDIDAS: GENERALIDADES PARA SABANA OCCIDENTE Y SABANA CENTRO}

La cuestión de análisis ambiental, reiteramos, aquí se hace desde la perspectiva de los actores de los territorios analizados. Por supuesto, se toman evidencias no solo de las visitas de campo sino también de los estudios realizados sobre la región capital. Para empezar, el conjunto de ecosistemas naturales que conforman la región (Preciado, 2012) son los que se alteran 
puesto que, aunque las actividades económicas se hagan sobre una porción de territorio, los impactos son sobre todo un sistema.

Los municipios de las dos provincias que aquí se tratan, son catalogados bajo la categoría de "Ecorregión Urbana", lo que se traduce, en términos ecológicos, en que su dinámica presenta una enorme importancia por los impactos que produce en los ecosistemas que los contienen. Como referente principal y estructurante, está el río Bogotá, a cuya cuenca pertenecen estos municipios.

No cabe la menor duda de que impactos producidos por el macrovector "asentamientos humanos" sobre varios recursos, o activos naturales como en este trabajo se denominan, "especialmente por la contaminación por concepto de descargas orgánicas y residuos sólidos" según la CAR (2004, p. 71), son preocupantes en términos ambientales. Cuestión que es reafirmada por la comunidad. De otro lado, la proximidad de Bogotá tiene una incidencia grande pues refuerza la función de municipios dormitorio que, con la llegada de empresas, demandan más suelo para vivienda de interés social (CAR, 2004, p. 62). En este caso, sabana occidente se está viendo más afectada por el impacto de los dos macrovectores: urbanización e industria.

No deja de llamar la atención, por lo demás, que en la región se presenta una caída de la industria, tal como lo demuestra Moncayo et al (2008), (2009, 2011) y Rincón (2009), expresado en traslados de empresas, en gran parte como bodegas y no como procesos productivos. Esto se traduce en escasa absorción de empleo y en el "avance de los servicios, buena parte de ellos realizados desde el sector informal y sin gran desarrollo de nuevas tecnologías" (Rincón, 2009).

La Figura 3 indica en forma general el fenómeno: en un punto de inflexión en la línea del tiempo, año 2000 , la presión de los dos macrovectores es evidente sobre el capital ecológico. Las expresiones de la comunidad y los estudios referenciados coinciden al respecto. 


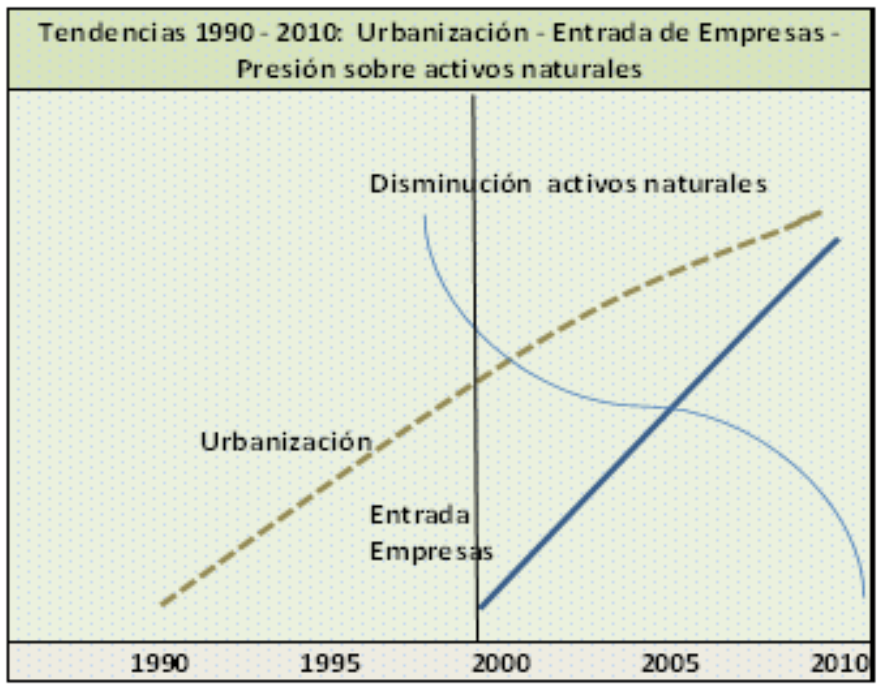

Fuente: El autor.

Figura 3. Tendencia general del proceso de transformación sabana centro y sabana occidente.

(Los anexos 3 y 4 recogen de manera sintética los hallazgos en los territorios. Los anexos 5 y 6 ilustran los momentos clave en la línea del tiempo para sabana occidente y sabana centro, respectivamente). A continuación se describen y analizan dichos hallazgos.

- Se hace evidente un proceso jerárquico, excluyente, no planificado ni participativo del proceso de expansión de los municipios.

- En general, cada municipio ha venido asumiendo un proceso de crecimiento -no desarrollo- de manera aislada y no en conjunto por provincia, mucho menos desde la región. Una voluntad para hacer una región metropolitana, por ejemplo, se pierde.

- Es indudable que dos factores clave -“Urbanización y Entrada de Empresas"- son los que han incidido de manera más fuerte y significativa en el tipo de crecimiento que ha tenido la región, en particular los municipios de las dos provincias.

- Por su cercanía a Bogotá, estos municipios sufren de manera directa el impacto de la expansión urbana de la ciudad, específicamente, la conurbación que trae consigo demandas de servicios fundamentales como educación, agua y servicios de transporte más eficientes (movilidad) que los mismos municipios no están en capacidad de ofertar en su totalidad.

- Las eventuales ganancias que en términos de balance fiscal los municipios han tenido, se ven en riesgo dado que la presión por ofrecer mejores servicios sociales, infraestructura vial y de servicios, a largo plazo tendrá un mayor costo para los entes territoriales.

- La vocación del suelo en estos municipios, que era rural agrícola, ha entrado, desde finales de los años noventa, en declive para dar paso a una incipiente vocación de uso del suelo semiindustrial, de bodegaje, parques industriales y residencial. 
- Para la época, la Ley 368 impulsó el diseño de los POT para todos los entes territoriales. Parece que estos no se hicieron con la respectiva información y difusión a la comunidad.

- También es claro que hay un conflicto entre Bogotá y los municipios en relación con el agua. Más allá de los pormenores, se presenta un descontento de la comunidad hacia Bogotá, dado que la fuente natural del recurso hídrico proviene de estos municipios.

- Como era de esperarse, la cuestión ambiental se vuelve más urgente de tratar. El uso del suelo que naturalmente era para la agricultura, al ser utilizado para la actividad industrial y/o residencial, ha implicado problemas de deterioro de los nutrientes del suelo; los humedales se han secado y usado para construir y se está excavando, sin ningún tipo de criterio técnico que permita cuidar los recursos naturales.

- El tema del agua es crucial. Surgen preguntas: ¿Quién maneja las fuentes hídricas? ¿Cómo se surten de agua? ¿Quiénes gestionan este recurso? La gestión se encuentra entre el dilema "Estado o Mercado". De todos modos, la cuestión del tema del agua es vital. La privatización y manejo del agua constituye un elemento de negociación clave y en fuente de poder.

- Otro aspecto en el que se comienza a tomar conciencia por sus inminentes implicaciones socioambientales, lo constituye la carga ambiental que genera el crecimiento de los municipios sobre el ecosistema. Con base en los supuestos de la economía ecológica (Martínez, 2008; Common \& Stagl, 2008; Pengue, 2008) se plantea que un proceso económico (producción, consumo) y en general actividades antrópicas, producen o generan energías negativas que se traducen en desechos que alteran el equilibrio ecológico. En palabras de los mismos participantes, no hay un proceso adecuado para la descarga de desechos. El mismo plan de proyectos conjuntos contempla este factor (Tabla 2), "Proyecto regional de disposición de residuos sólidos". Comienza a sentirse una inquietud al respecto dada las alarmas que al respecto diversos expertos vienen haciendo.

- El escenario de enfrentarse a la cuestión de los recursos naturales y su gestión y administración, supone además enfrentarse al problema del papel de la comunidad en relación con estos. Es decir, hablamos de una gobernanza de los recursos naturales y de la acción colectiva.

- Al otorgarse permisos para construir cerca de la ronda de los ríos, refleja la inconsistencia al momento de ordenar el territorio; el agua no es referente para ordenarlo.

- Cuando la comunidad afirma que hubo un cubrimiento de todas las zonas del territorio, sin duda encuentra que lo ambiental no es considerado y de algún modo esto demuestra igualmente la poca capacidad de la gestión pública para enfrentar los intereses del sector privado.

- En ese sentido: ¿Qué capacidad de autonomía tiene el municipio para determinar su crecimiento urbanístico y orientar sus eventuales nuevos ingresos fiscales al desarrollo de infraestructura y oferta de servicios sociales de calidad?

- La ocupación de humedales o zonas de reserva ecológica es algo que no había sido preocupación de la comunidad.

- El abrupto cambio se da también sin una visión de ordenamiento respetando la estructura ecológica. 
- Se ha presentado una mutación en la dinámica socioambiental de los territorios. La expresión más clara de esa mutación, lo evidencia la comunidad al decir que el "agua se acabó", "desaparecieron los pozos profundos, la tierra ya no sirve por salinización".

- Una cuestión que también toca lo ambiental es lo relacionado con el saneamiento básico. Las acciones se vuelcan a adecuar la infraestructura a estas actividades económicas, pero olvidan u omiten la generación de una estructura que soporte la carga de desechos, los impactos nefastos sobre la estructura ambiental, etc., que incide a su vez en el saneamiento básico.

- Los municipios no cuentan con Sistemas de Información Geográfica que les permita tener información de calidad frente al impacto sobre sus ecosistemas de las actividades de carácter antrópico. En 1993, en un importante estudio de Gustavo Montañez sobre la región capital, publicado en la revista Cuadernos de Geografía del Departamento de Geografía de la Universidad Nacional de Colombia (1993), se concluía que era urgente que estos municipios contaran con este instrumento esencial para la toma de decisiones de política pública en materia ambiental. 20 años después, no se ha hecho nada al respecto. Los funcionarios entrevistados, coinciden en afirmar que se trabaja todavía sin las condiciones técnicas necesarias para este ámbito de la política pública.

- Se observa la misma cultura en la política de desarrollo regional que el país ha llevado, en el sentido de no trabajar desde una perspectiva integral y pluralista con los diversos actores sociales (Quintero, 2009, p. 42). Igualmente, comenta este autor, que el desarrollo regional ha sido un proceso liderado por intereses de grupos de mucho poder, sin continuidad y sin visión de integración nacional-regional. La región capital, no ha sido ajena a esta tendencia.

- Gran parte de la sabana de Bogotá, en particular los territorios objeto de análisis, dejaron en la última década de tener actividad agropecuaria significativa y de ser fuente alimentaria de Bogotá, para pasar a tener con la capital una serie de relaciones complejas que alteran significativamente la dimensión ambiental (Preciado, 2009, p. 75), lo que sin duda se evidenció en el trabajo con la comunidad y las salidas de campo efectuadas.

\section{RECOMENDACIONES}

Un trabajo de esta naturaleza, donde la base de la información es la voz de las organizaciones de la comunidad que tienen presencia en un determinado territorio, por supuesto que no puede considerarse un estudio "cuantitativamente" determinante. No obstante, puede constituirse en un referente fundante para ahondar de manera participativa e integral en una de las problemáticas que no solo en estos territorios sigue siendo de alguna manera marginal, sino que a nivel global se convierte en un reto que no da más tiempo para enfrentar.

En esa medida, los aprendizajes del trabajo de campo, cuyo enfoque teórico le da asimismo rigurosidad para interpretar los 
hallazgos, constituyen base para profundizar en el conocimiento de los municipios en virtud de los cuales se avance hacia la consolidación de regiones integradas no solo desde lo políticoadministrativo, sino también desde la acción colectiva hacia el objetivo de alcanzar óptimos niveles de bienestar social, ambiental y económico.

En virtud de lo expuesto se pueden resumir unas recomendaciones básicas a los municipios y organizaciones, las cuales pueden servir de base para avanzar hacia un proceso participativo de construcción de lo local-regional, en un mundo globalizado:

- Avanzar en la visión de concebir el agua como referente de ordenamiento de los territorios. Ello porque el crecimiento urbano implica un uso adecuado del recurso hídrico, acceso a agua potable, prevención de riesgos, que impactan los territorios en escenarios de cambio climático (OAB, 2014).

- La participación de todos los actores es vital. La cuestión de "la gobernanza de los activos naturales" se convierte en un elemento para cambiar el rumbo que hasta ahora ha tenido la política ambiental en la región: aislada, sectorizada, reactiva y sin una visión más ecológica. Es decir, empezar a trabajar un cambio de paradigma que supere el simple "desarrollo sostenible" para pasar, desde la acción colectiva, a la "ecologización de los territorios" (Franchomme et al., 2013, p. 2) entendido no como la domesticación de la naturaleza, sino como la comprensión de que la biodiversidad adquiere valor en "el espacio de lo cotidiano". A su vez, esto implica la necesidad de "transferir" la ecología al ordenamiento del territorio, en cuanto asumir el valor de cada una de las actividades de las sociedades que no se restrinja al simple cuidado de un árbol, de una vía, etc., sino como una acción política de las comunidades. También, como una forma profunda de ver e internalizar el ambiente, en relación con la mente y la paz (Carrizosa, 2007).

- En ese orden de ideas, la conciencia sobre lo ecológico en los territorios debe superar la educación ambiental básica, cuyo sentido se reduce a meras campañas acerca del buen cuidado de la naturaleza, para pasar a acciones de política pública sistémicas y de largo plazo.

- Los municipios no pueden seguir asumiendo posiciones "feudales" o de orden simplemente administrativo, olvidando que los problemas ambientales no conocen fronteras políticoadministrativas. Se requieren acciones integrales de conjunto y con perspectivas y enfoques novedosos.

\section{REFERENCIAS}

- Boix Domenech, R. (2004). Redes de ciudades y externalidades. Investigaciones Regionales, 4, 5-27. Recuperado el 5 de septiembre de 2013 de http://www.redalyc. org/articulo.oa?id=28900401

- CEPEC - Universidad del Rosario. (2011). Planes de competitividad en 4 provincias de Cundinamarca: Almeidas, Alto 
Magdalena, Tequendama y sabana Occidente. Recuperado de http://www.urosario.edu.co/urosario_files/c7/c75acb75-be29 -49c8-8e50-f45bd4f96169.pdf

- Corporación Autónoma de Cundinamarca -CAR- (2004). Plan de gestión ambiental regional 2001-2010. CAR, Bogotá.

- Carrizosa, J. (2007). Mente, ambiente y paz. Gestión y Ambiente, 10(1), 43-51.

- Castiblanco, C. (2007). La economía ecológica: una disciplina en busca de autor. Gestión y Ambiente, 10(3), 7-21.

- Common, M. \& Stagl, S. (2008). Introducción a la economía ecológica. Madrid: Ed. Reverte.

- DANE (2014) Estimaciones de Población Nacional, Departamental y Municipal 2005 - 2020. www.dane.gov.co

- Fals Borda, O. (2000). El territorio como construcción social. Revista Foro, 38, 45-51.

- Franchomme, M. et al. (2013). La biodiversité "aménage-t-elle" les territoires? Vers une écologisation des territoires. Development durable et territoires, 4(1). Recuperado el 20 de agosto de 2013 de http://developpementdurable.revues.org/9749

- Garay, L.J. (1999). Globalización y crisis. ¿Hegemonía o corresponsabilidad? Bogotá: Tercer Mundo Editores - Colciencias.

- Gobernación de Cundinamarca (2010). Balance del proceso de integración regional entre Bogotá - Cundinamarca 2008 - 2011. Gobernación de Cundinamarca, Bogotá.

- Gómez, L.J. (2010). Introducción a la economía ecológica. Bogotá: Ed. Universidad Nacional.

- Harvey, D. (2007). Espacios del capital. Hacia una geografía crítica. Madrid: Ed. Akal.

- Landínez, R. (2011). Indicadores sobre Medio Ambiente: Avances para una propuesta relacional con indicadores de Pobreza. Pre-til - Investigar para hacer ciudad, 25, 39-54.

- Lefebvre, H. (1973) El derecho a la ciudad. Ed. Península, Barcelona.

- Márquez, G. (2001). De la abundancia a la escasez. La transformación de ecosistemas en Colombia. En Palacios, G. (Ed.), La naturaleza en disputa. Bogotá: Universidad Nacional de Colombia - UNIBIBLOS.

- Martínez, J (2008) Decrecimiento sostenible: París abril del 2008 En: Revista de Economía Ecológica No. 35 pp 51 - 58. Ed. Icaria, Barcelona.

- Martínez, J. (1998). Curso de economía ecológica. Madrid: Red de formación ambiental, PNUMA.

- Mejía, L. (2009). Apuntes para una aproximación a la caracterización de la región capital. SDP - Dirección de integración regional, nacional e internacional. Recuperado de http://www.sdp.gov.co/portal/page/portal/PortalSDP/Seguimie ntoPoliticas/

politicalntegracionRegional/Banco\%20de\%20Documentos\%2 0de\%20

Integraci\%F3n\%20Regional/DocumentosTrabajo/Apuntes\%20 de $\% 20$

Caracterizaci\%F3n\%20Regional.pdf Enero 28 de 2014

- Moncayo, E (2011) Crecimiento, cambio estructural y desindustrialización en Colombia 1975 - 2000. Universidad Nacional de Colombia, Bogotá 
- Moncayo, E. (2009). Globalización asimétrica y desarrollo precario: una perspectiva andina. UNU - CRIS Working Paper.

- Moncayo, E et al (2008) Dinámicas regionales de la industrialización. Análisis comparativo de Cundinamarca y Bogotá, D.C. Universidad Central. Bogotá

- Montañez, G (1993) Una metodología del SIG para la planeación y gestión municipal sobre manejo de recursos naturales. En: Cuadernos de Geografía. Departamento de Geografía, Universidad Nacional de Colombia. Vol IV No. 1 - 2, 1993, pp 1143

- Observatorio Ambiental de Bogotá -OAB-. (2014). El territorio urbano se ordena alrededor del agua. Recuperado de http://oab.ambientebogota.gov.co/comunidad.shtml? apc $=m 1 h 1---\& x=7496$

- Pengue, W (2008) La economía ecológica y el desarrollo en América Latina. Recuperado de http://www.ecoportal.net/Temas_Especiales/Economia/la_eco nomia ecologica_y_el_desarrollo_en_america_latina Febrero 5 de 2014

- Preciado, J. (2012). La dimensión ambiental como eje estructurante de la región metropolitana de Bogotá. Recuperado de http://aciur.net/site/wp-content/uploads/2012/11/5_JairPreciado -Beltr\%C3\%A1n.pdf

- (2009). Bogotá Región: crecimiento urbano en la consolidación del territorio metropolitano. En Memorias Seminario Internacional Bogotá y Cundinamarca. Avances y perspectivas para la integración regional (pp. 67-79). Bogotá: Universidad Distrital - CAR.

- Quintero, O. (2009). Una mirada sobre la reconfiguración territorial en Colombia - La subregión sabana y la región capital. En Memorias Seminario Internacional Bogotá y Cundinamarca. Avances y perspectivas para la integración regional (pp. 39-66). Bogotá: Universidad Distrital - CAR.

- Rincón, P. (2009). Hacia la definición de la estructura funcional de Bogotá - región Central. Recuperado de http://www.aciur.net/images/documentos/Hacia_Definicion_ Estructura_Bogota-Rincon_Potricia-Documento.pdf

- Secretaría de Planeación de Cundinamarca (2014) http://www.cundinamarca.gov.co/wps/portal/Home/Secretaria sEntidades.gcl Secretariadeplaneacion/SecretariadeplaneacionDespliegue/a sestadisticas contenidos/csecreplanea_estadis_visor

- Soja, E. (2006). Postmetrópolis: estudios críticos sobre las ciudades y las regiones. Madrid: Ed. Traficantes de Sueños.

- Tomadoni, C. (2007). A propósito de las nociones de espacio y territorio. Gestión y Ambiente, 10(4), 53-65.

- Von Martin, A. (1932) Sociología del renacimiento. Segunda reimpresión, 1993. FCE, Bogotá.

1. Trabajo en el marco del proyecto "Análisis de los procesos de transformación en un Territorio de la región capital”, Programa de 
economía, Universidad Piloto de Colombia (UPC). Este trabajo no presenta conflicto de intereses y su financiación estuvo a cargo de la Dirección de Investigaciones de la UPC.

2. Profesor Programa de Economía, Universidad Piloto de Colombia. Economista. Magíster en Planeación y Administración del Desarrollo Regional. CIDER, Universidad de los Andes. miguellandinez@unipiloto.edu.co

3. Como lo señalan Common \& Stagl $(2008$, p. 4), en las últimas 3 décadas del siglo XX fue evidente que la actividad económica humana tenía perjudiciales efectos sobre el medio ambiente natural y que a su vez esto afectaba lo económico de las futuras generaciones.

4. Por ejemplo, Márquez (2001) en un estudio señala cómo nuestro país estaba cubierto completamente de selvas, sabanas, páramos y humedales. Sin embargo, hoy en día gran parte de los ecosistemas han sido remplazados por potreros, cultivos, asentamientos humanos y obras de infraestructura.

5. Ver: EarthTrends del World Resources Institute (WRI), de la División de Estadística del Departamento de Asuntos Económicos y Sociales de las Naciones Unidas y las bases de datos del Banco Mundial.

6. El término "sinecismo' -el cual es usado por Edward Soja- (del

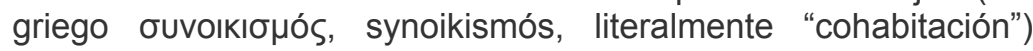
alude a un proceso histórico por el cual una serie de poblaciones aisladas se juntan formando una Ciudad-Estado para mayor protección. Ello supuso la aparición de las polis en la Antigua Grecia.

(Tomado http://www.babylon.com/definition/sinecismo/Spanish).

Para citar este artículo: Landínez León M. R. (2014). De lo rural a lo urbano: "el caso de dos provincias de la región capital como geografía de la transformación socioambiental. Percepciones desde la comunidad". Revista Luna Azul, 41, 89-115. Recuperado http://lunazul.ucaldas.edu.co/index.php?option=content\&tas k=view\&id=1057 